\title{
Role of 18 fluorine-fluorodeoxyglucose positron emission tomography/computed tomography in assessment of neoadjuvant chemotherapy response in breast cancer patients
}

\author{
Eslam Abdul Salam Sarhan ${ }^{1}$, Mervat Ibrahim El Gohary², Lobna Abd El Moneim² and Susan Adil Ali ${ }^{2 *}$
}

\begin{abstract}
Background: Neoadjuvant chemotherapy (NAC) is a therapeutic option for locally advanced breast cancer and is aiming to reduce tumor volume for breast conservation. Accurate assessment of residual tumor after NAC is a crucial for determining the outcome and survival of the patients. Eighteen fluorine-fluorodeoxyglucose positron emission tomography/computed tomography $\left({ }^{18} \mathrm{~F}-\mathrm{FDG} \mathrm{PET} / \mathrm{CT}\right)$ has been recently used as a reliable tool to evaluate response to treatment due to combined morphologic and metabolic information. The aim of this study was to assess the value of ${ }^{18} \mathrm{~F}-\mathrm{FDG}$ PET/CT in evaluation of response to NAC in a sample size of recently diagnosed 30 locally advanced breast cancer patients, who were referred for ${ }^{18}$ F-FDG PET/CT scanning before and after NAC. The morphologic and metabolic response was evaluated and compared to histopathologic findings.

Results: ${ }^{18} \mathrm{~F}$-FDG PET/CT detected 23 responders and 7 non-responders among the examined 30 breast cancer patients, compared to 20 responders and 10 non-responders detected by $C T$ alone. ${ }^{18} \mathrm{~F}-\mathrm{FDG}$ PET/CT showed sensitivity, specificity, positive predictive value, negative predictive value, and accuracy of 95.5\%, 75\%, 91.3, 85.7, and $90 \%$, respectively, compared to $81.8 \%, 75 \%, 90,60$, and $80 \%$, respectively, achieved by CT alone.

Conclusion: ${ }^{18} \mathrm{~F}-\mathrm{FDG}$ PET/CT is a reliable single whole body imaging tool which can be used in monitoring of NAC response in patients with locally advanced breast cancer showing higher sensitivity and accuracy compared to $C T$ alone.
\end{abstract}

Keywords: Breast cancer, Neoadjuvant chemotherapy, ${ }^{18}$ F-FDG PET/CT, RECIST, PERCIST

\section{Background}

Breast cancer is the most commonly diagnosed lifethreatening cancer in females and the leading cause of cancer death among women [1]. Once diagnosed, the tumor stage has to be determined accurately to choose appropriate therapy and know the prognosis [2]. Neoadjuvant chemotherapy (NAC) is a management option for locally advanced breast cancer. Its goal is to reduce tumor

\footnotetext{
* Correspondence: dr.susanadil@hotmail.com

${ }^{2}$ Radiodiagnosis Department, Ain Shams University, Cairo, Egypt

Full list of author information is available at the end of the article
}

volume for the purpose of breast conservation. Accurate assessment of residual tumor after NAC is a crucial prognostic factor for determining the outcome and survival of the patients [3]. Anatomic response criteria often underestimate the chemotherapeutic effect. Imaging of metabolic pathways serves as an alternative way for visualizing the treatment effects, as metabolic reduction within the tumor often precedes the anatomic response to therapy [4]. Positron emission tomography (PET) with 18 fluorine $\left({ }^{18} \mathrm{~F}\right)$ flurodeoxyglucose (FDG) has an important role in oncology, and its role in breast cancer management is evolving [5-9]. It has been used to evaluate the clinical 
response to NAC in breast cancer patients because metabolic reduction often occurs early in the course of therapy and precedes reduction in size of the tumor. Semiquantitative assessment of ${ }^{18} \mathrm{~F}$-FDG uptake has been reported as a strong predictor of pathologic and clinical response. Metabolic reduction detected before and after NAC using PERCIST (PET Response Criteria In Solid Tumor) can provide early information on potential tumor response [4]. The aim of this work was to assess the added value of ${ }^{18} \mathrm{~F}$-FDG PET/CT scan in evaluation of response to neoadjuvant chemotherapy in locally advanced breast cancer patients before surgery.

\section{Methods}

\section{Patients}

This prospective study was conducted in the period from March 2017 to October 2019 and included 30 female patients with locally advanced breast cancer (a total of 31 lesions) who were referred to perform baseline pretreatment and end of therapy ${ }^{18} \mathrm{~F}$-FDG PET/CT scans (before starting and after completion of NAC). Approval of the institutional review board and written informed consents from all patients was obtained before the start of this study.

\section{Inclusion criteria}

Any female patient between 20 and 70 years old with histologically confirmed diagnosis of locally advanced breast carcinoma (Large breast tumors $>5 \mathrm{~cm}$ in diameter, cancers that involve the skin of the breast or the underlying muscles of the chest, or cancers that involve multiple local lymph nodes) who did not receive any therapy (including recurrent breast cancer).

\section{Exclusion criteria}

Any patient had inflammatory breast cancer, known to have contraindications for radiation (e.g., pregnant females), patients with renal impairment or had high blood glucose levels at the time of the study, and patients underwent any surgical intervention or received radiotherapy as a line of treatment.

\section{Patient preparation}

Patients were fasting for a minimum of $6 \mathrm{~h}$ before the scan with good hydration. Exercises were avoided for a minimum of $24 \mathrm{~h}$ (ideally, $48 \mathrm{~h}$ ) before the scan. Kidney function tests were reviewed and confirmed to be within normal limit $(0.6-1.3 \mathrm{mg} / \mathrm{dL})$ with pre-scanning blood glucose level estimation (accepted between 150 and 200 $\mathrm{mg} / \mathrm{dL}$ including diabetic patients who were advised to properly control their blood glucose level before examination) and insertion of ante-cubital intravenous cannula.

\section{Technique of 18F-FDG PET/CT scan}

The radioactive tracer $\left({ }^{18} \mathrm{~F}\right.$-FDG) was injected intravenously in a dose of $0.1 \mathrm{mCi} / \mathrm{kg}$ body weight. All patients were kept in a warm temperature room and asked to rest without vigorous activity and void just before imaging. Scanning by a hybrid PET/CT scanner (Ingenuity TF 64 combining a modular, LYSO-based PET component with a 64-channel CT component, Philips Healthcare, Cleveland, OH, USA) was performed $60 \mathrm{~min}$ after injection. The patient was positioned supine on the table. Initial single-phase contrast material-enhanced helical CT was performed following injection of $125 \mathrm{~mL}$ of a low-osmolarity iodinated contrast medium (Optiray 350 ) at a rate of $4 \mathrm{~mL} / \mathrm{s}$ by using a power injector. A whole body CT study (from the head to mid-thigh) scanning was obtained using $110 \mathrm{~mA}, 110 \mathrm{kV}, 0.5 \mathrm{~s}$ tube rotation time, and $3.3 \mathrm{~mm}$ section thickness. After CT scanning, PET scan covering the same field of view was obtained immediately. Six to seven bed positions are planned in the three-dimensional acquisition mode for scanning the entire patient with 3-5-min acquisition at each bed position. Images were transferred to a dedicated workstation to be reconstructed and displayed in axial, coronal, and sagittal planes. Baseline (pre-treatment) studies were performed within a week prior to the start of NAC, and post-treatment studies were performed 3-4 weeks after completion of NAC.

\section{Image analysis}

Images were analyzed by two experienced radiologists having 7 and 10 years of experience in PET/CT imaging with $100 \%$ interobserver agreement. Analysis of CT images was done by visual inspection with selection of target lesions and measuring their dimensions. Analysis of $\mathrm{PET} / \mathrm{CT}$ images was done by visual inspection with quantitative calculation of FDG uptake of the lesions corrected to lean body mass ( $\left.\mathrm{SUL}_{\text {peak }}\right)$. They used the PERCIST 1.0 criteria on PET/CT interpretation and the RECIST 1.1 criteria on CT interpretation in both preand post-NAC scans for all the studied patient as in Table $1[10]$.

$\mathrm{SUV}_{\max }$ was defined as the maximum concentration in the primary tumor (injected dose/body weight). Maximum or average SUV has been used in many studies to quantify tumor FDG uptake, but have specific limitations. Maximum SUVs are sensitive to image noise and overestimate tumor FDG uptake in mildly FDG avid lesions. The goal of $\mathrm{SUV}_{\text {peak }}$ is to avoid these limitations. $\mathrm{SUV}_{\text {peak }}$ was calculated using a $1.2-\mathrm{cm}$ diameter volume region of interest (VOI) placed on the hottest site of the primary tumor, then normalized to lean body, mass and abbreviated as $\mathrm{SUL}_{\text {peak }}\left(\mathrm{SUV}_{\text {peak }} \times\right.$ [lean body mass]/ [total body mass]). The percentage of change in $\mathrm{SUL}_{\text {peak }}$ was calculated using the following equation: (pre-NAC 
Table 1 RECIST 1.1 and PERCIST 1.0 criteria for therapeutic response evaluation [10]

\begin{tabular}{|c|c|c|}
\hline & RECIST 1.1 & PERCIST 1.0 \\
\hline \multirow[t]{2}{*}{ Responders } & CR Disappearance of target lesions & $\begin{array}{l}\text { CMR The target lesion shows absent FDG uptake or shows SUL } L_{\text {peak }} \text { less } \\
\text { than the liver. }\end{array}$ \\
\hline & $\begin{array}{l}\mathrm{PR} \geq 30 \% \text { decrease in the sum of the diameter of the } \\
\text { target lesions }\end{array}$ & PMR $\geq 30 \%$ decrease or at least 0.8 SUL peak decrease \\
\hline \multirow{2}{*}{$\begin{array}{l}\text { Non } \\
\text { responders }\end{array}$} & SD Increase in size $<20 \%$ or decrease size $<30 \%$ & SMD Increase or decrease in the $S U L_{\text {peak }}$ of less than $30 \%$ \\
\hline & $\begin{array}{l}\text { PD } \geq 20 \% \text { increase in the sum of the diameter of the } \\
\text { target lesions or newly developed lesions }\end{array}$ & $\begin{array}{l}\text { PMD The target lesion shows an increase in } S U L_{\text {peak }}>30 \% \text { or at least } 0.8 \\
\text { SUL }\end{array}$ \\
\hline
\end{tabular}

$C R$ complete response, $P R$ partial response, $S D$ stationary disease, $P D$ progressive disease, $C M R$ complete metabolic response, $P M R$ partial metabolic response, $S M D$ stationary metabolic disease, $P M D$ progressive metabolic disease

$\mathrm{SUL}_{\text {peak }}$-post-NAC SUL $\left.\mathrm{Seak}_{\text {pea }}\right) /$ pre-NAC SUL peak $\times 100$. $\mathrm{SUL}_{\text {peak }}$ should be 1.5 times or more that of the liver $\mathrm{SUL}_{\text {mean }}$ (in a 3-cm diameter spherical ROI on the normal right lobe). In case of diseased liver, mediastinal blood pool $\mathrm{SUL}_{\text {mean }}$ can be used as an alternative internal reference in order to bypass the pitfalls of improper dosage and poor preparation $[11,12]$.

\section{Histological evaluation}

A baseline immuno-histochemical characterization was also performed, evaluating the hormone receptor indexes (estrogen receptor ER and progesterone receptor $\mathrm{PR})$. Tumors were then classified into the various molecular subtypes including luminal A, luminal B, triple negative/basal-like, and HER2+ [13].

Histopathologic tumor regression was semi-quantitatively graded by an experienced pathologist (had 10 years of experience) based on the Miller-Payne grading system. Patients were divided into two groups: pathologic responders and non-responders. Patients showing Miller-Payne grades 3 , 4, and 5 were categorized as responders, and patients showing grades 1 and 2 were non-responders (Table 2) [14].

\section{Statistical analysis}

The collected data were coded, entered, presented, and analyzed by computer using a data base software program, Statistical Package for Social Science (SPSS) version 20. Qualitative data were represented as frequencies and percentages. For quantitative variables, mean, standard deviation (SD), and range were computed. For evaluating quantitative variables in the same group, Wilcoxon signed-rank test was used. Chi-square (X2) test was used to detect relation between different qualitative variables. Spearmen's correlation ( $r$ ) was used to correlate tumor size on CT and PET. Sensitivity, specificity, positive predictive value (PPV), negative predictive value (NPV), and accuracy were calculated at $95 \%$ CI to measure the validity. The results were considered statistically significant and highly statistical significant when the significant probability ( $P$ value) was $<0.05$ and $<0.001$, respectively.

\section{Results}

Of the studied thirty patients, 29 patients had unilateral, and one patient had bilateral primary breast tumors. The patients ranged in age between 36 and 68 years with mean age of $53.57 \pm 12.27$ years. Seventeen patients $(56.7 \%)$ were post-menopausal, and thirteen patients (43.3\%) were premenopausal. Among the examined thirty patients, 29 patients had nodal metastasis; yet, no any patient had distant metastasis.

According to Tru-cut biopsy, 29 patients were diagnosed with IDC (96.7\%), and 1 patient had ILC (3.3\%). Regarding histological grade, 18 patients $(60 \%)$ had GII tumor, and 12 patients (40\%) had GIII tumor. Regarding molecular subtypes, $50 \%$ of tumors (15 patients) were classified as luminal A subtype, 20\% (6 patients) as luminal B, $13.3 \%$ (4 patients) as HER2 + subtype, and 16.7\% (5 patients) as the triple negative/basal-like subtype.

On baseline PET CT studies, the size of the primary tumor ranged from 1.6 to $6.6 \mathrm{~cm}$ (mean $3.64 \pm 1.36$ ), and the $\mathrm{SUL}_{\text {peak }}$ ranged from 2.5 to 15 (mean $6.96 \pm 3.81$ ). There was statistically positive correlation $(P$ value $<0.05)$

Table 2 Miller-Payne grading system for histopathologic response evaluation [14]

\begin{tabular}{ll}
$\begin{array}{l}\text { Miller-Payne } \\
\text { system }\end{array}$ & Histopathologic findings \\
\hline Grade $\mathbf{1}$ & No change or some alteration to individual malignant cells, but no reduction in overall cellularity \\
Grade $\mathbf{2}$ & A minor loss of tumor cells, but overall, cellularity is still high, up to $30 \%$ loss \\
Grade 3 & Between an estimated $30 \%$ and $90 \%$ reduction in tumor cells \\
Grade $\mathbf{4}$ & A marked disappearance of tumor cells such that only small clusters or widely dispersed individual cells remain $>$ 90\% loss of \\
Grade $\mathbf{5}$ & tumor cells \\
\hline
\end{tabular}


between pre chemotherapy tumor size on $\mathrm{CT}$ and $\mathrm{SUL}_{\text {peak }}$ on PET among the studied patients (Fig. 1).

On follow-up PET/CT studies, the size of the primary tumor ranged from 0.0 to $7.6 \mathrm{~cm}$ (mean $2.27 \pm 1.25$ ), and the $\mathrm{SUL}_{\text {peak }}$ ranged from 0.0 to 24.7 (mean $3.43 \pm$ 4.43). There was highly statistical positive correlation $(P$ value $<0.001$ ) between post-chemotherapy tumor size on CT and $\mathrm{SUL}_{\text {peak }}$ on PET among the studied patients (Fig. 2).

\section{Evaluation of treatment response}

Twenty patients (66.7\%) showed SD (less than 30\% decrease in longest tumor diameter) and ten patients (33.3\%) showed PR (at least 30\% decrease in longest tumor diameter) according to RECIST 1.1. However, based on PERCIST 1.0, five patients (16.7\%) showed CMR, eighteen patients (60\%) showed PMR (Figs. 3 and 4), four patients (13.3\%) showed SMD (Fig. 5) and three patients (10\%) showed PMD (Fig. 6).

According to the Miller-Payne system for histopathologic response evaluation, 4 patients (13.3\%) showed complete pathologic response (grade 5), 18 patients (60\%) showed partial response (grades 3 and 4), and 8 patients $(26.7 \%)$ had no response (grades 2 and 1 ).

So, the highest percentage of the studied patients is responder to NAC according to RECIST 1.1, PERCIST 1.0, and histopathology representing 66.7\%, 76.7\%, and 73.3\%, respectively (Table 3, Fig. 7).

According to RECIST 1.1, 18 patients were true positive, and 2 were false positive among the 20 responders, while 6 patients were true negative and 4 were false negative among the 10 non-responders. Therefore, the sensitivity, specificity, PPV, NPV, and accuracy of CT based-RECIST 1.1 after NAC were $81.8 \%, 75 \%, 90,60$, and $80 \%$, respectively.

According to PERCIST 1.0, 21 patients were true positive, and 2 were false positive among the 23 responders, while 6 patients were true negative and 1 was false negative among the 7 non-responders. Therefore, the sensitivity, specificity, PPV, NPV, and accuracy of PET basedPERCIST 1.0 after NAC were 95.5\%, 75\%, 91.3, 85.7, and $90 \%$, respectively (with $30 \%$ change in $\mathrm{SUL}_{\text {peak }}$ as a cutoff point).

Thus, the therapeutic response evaluation based on PET/CT (PERCIST 1.0) showed higher sensitivity, PPV, NPV, and accuracy compared to the response evaluation which was based on CT alone (RECIST 1.1).

FDG uptake after NAC was observed in 1 out of the 4 patients in which pathologic complete response was achieved, and this was considered as false positive result as it was proved to be of inflammatory nature by histopathologic examination with no malignant cells detected. Furthermore, pathologic complete response could not be achieved in 1 out of 5 patients that did not show any abnormal FDG uptake in PET/CT, and this was considered false negative PET result as malignant cells were detected in histopathology.

There was no statistically significant difference between the size or $\mathrm{SUL}_{\text {peak }}$ of pre-and post-treatment breast lesions and age, menopausal status, tumor localization, clinical stage, and tumor grade (Tables 4, 5, 6, and 7).

\section{Discussion}

NAC can induce shrinkage of the breast tumor, improving its operability and increasing the rate of conserving breast surgery. However, it is difficult to assess residual neoplasia especially in patients who are well responded to treatment [15].

Therapeutic response was assessed on the basis of change in measurement of tumor size before and after treatment. However, significant advances in structural and functional imaging during the past two decades lead to improvement in evaluation of the treatment response [16]. ${ }^{18}$ F-FDG PET/CT can quickly and efficiently assess

\section{$r=0.472$ \\ $\mathrm{P}=0.008$}

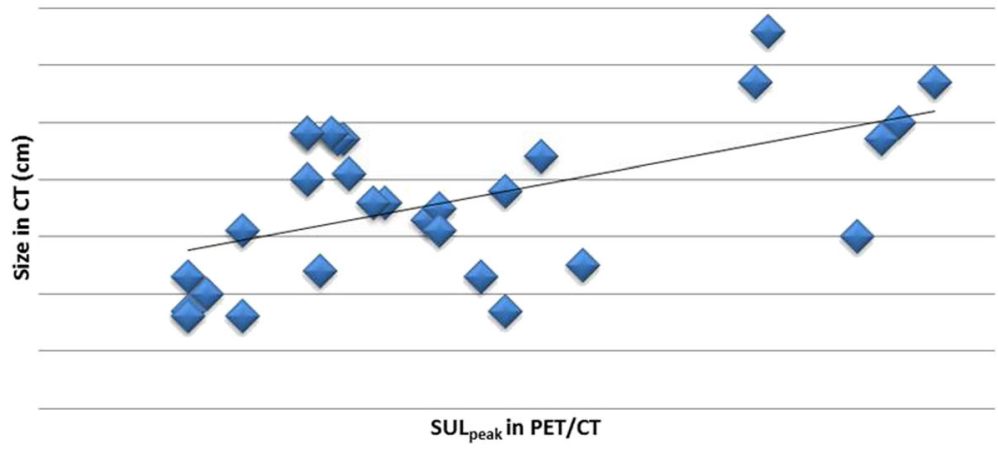

Fig. 1 Correlation between pre-chemotherapy tumor size and SUL peak among the studied patients 


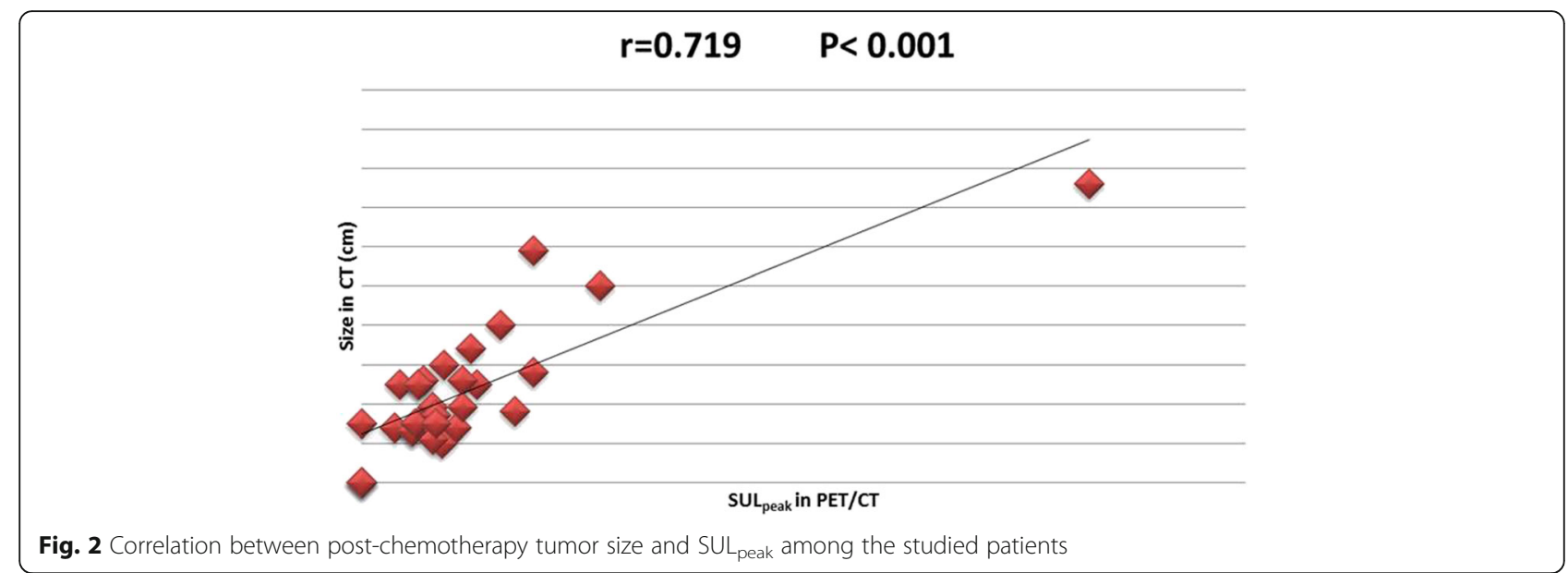

malignant tumor response to treatment, including breast cancer, by comparing baseline scan prior to and following 1 or 2 cycles of treatment [17-22]. It can demonstrate metabolic changes (much earlier than morphological changes in conventional imaging modalities) semi-quantitatively by calculating the $\mathrm{SUV}_{\max }$ which indicates the 18F-FDG uptake [23].

Using PET/CT for the identification of responders to treatment for breast cancer has been investigated in several clinical studies. Previous study by Jones el al. reported that PET predicts complete pathologic response, following a single pulse of chemotherapy, with sensitivity $90 \%$ and specificity $74 \%$ [24].
Other trial by Coudert et al. showed that early PET/ $\mathrm{CT}$ was used to identify early responders to neoadjuvant therapy following two cycles, and pathological complete responses were noted in 37 (53.6\%, 95\% CI 41.2-65.7) of the PET-predicted responders and 6 (24.0\%, 95\% CI 9.445.1) of the non-responders [25].

Also, a prospective study conducted by Pahk et al, over 27 patients of locally advanced breast cancer conclude that interim ${ }^{18}$ F-FDG PET/CT is a valuable method for predicting early response of neoadjuvant chemotherapy [26].

A study done by Yildirim et al. included 51 of locally advanced breast cancer patients who received NAC and retrospectively analyzed. It revealed that the PET/CT

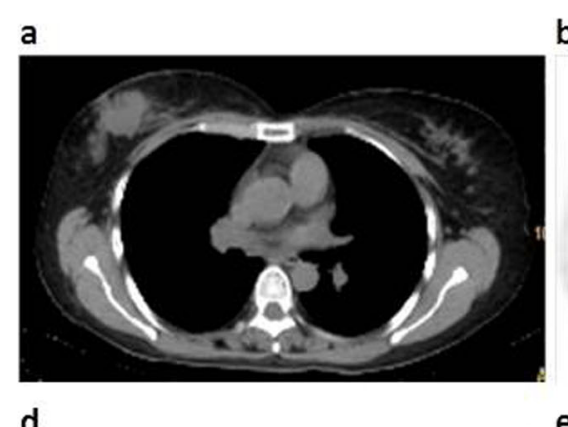

d

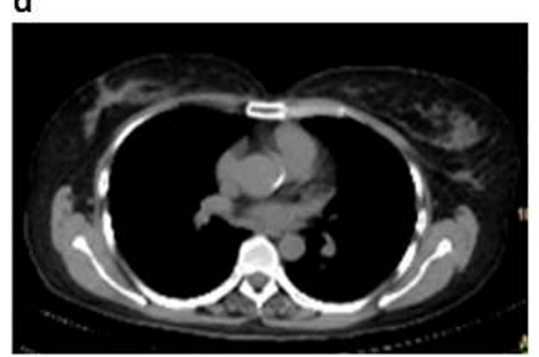

b

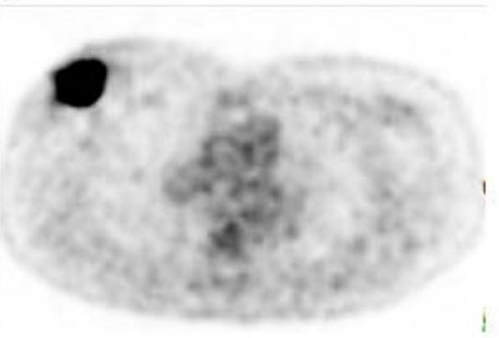

e

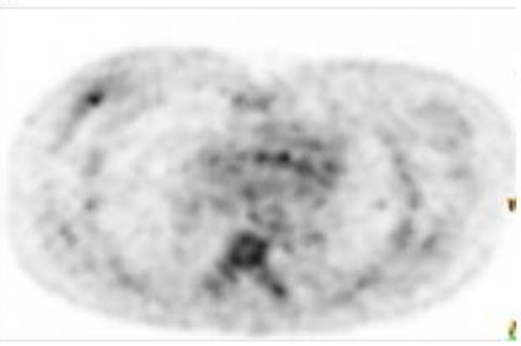

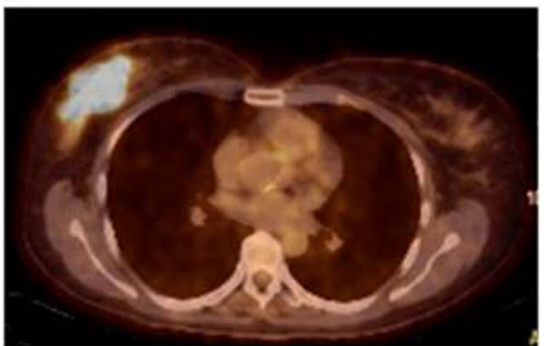

f

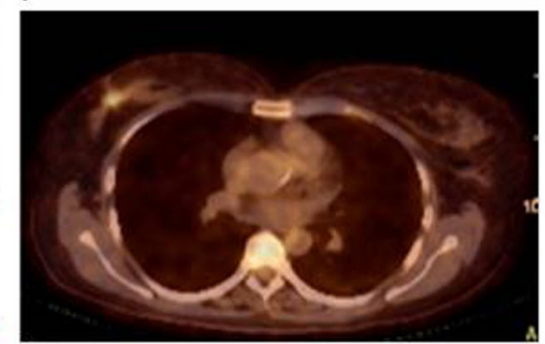

Fig. 348 years old female patient presented with clinically palpable right breast mass biopsy revealed IDC grade III. a Axial CECT image revealed right breast speculated soft tissue mass lesion measuring about $55 \times 60 \mathrm{~mm}$ that was eliciting dense tracer fixation reaching 13.5 SUL $L_{\text {peak }}$ in axial PET (b) and fused PET/CT (c) images. On follow-up after completion of chemotherapy, marked morphologic and metabolic regression of the mass was noted in the form of reduction in size (reaching $10 \times 12 \mathrm{~mm}$ ) in axial CECT image (d) denoting partial response and reduction in SUL $L_{\text {peak }}$ (reaching 2.7) in axial PET (e) and fused PET/CT (f) images denoting partial metabolic response 

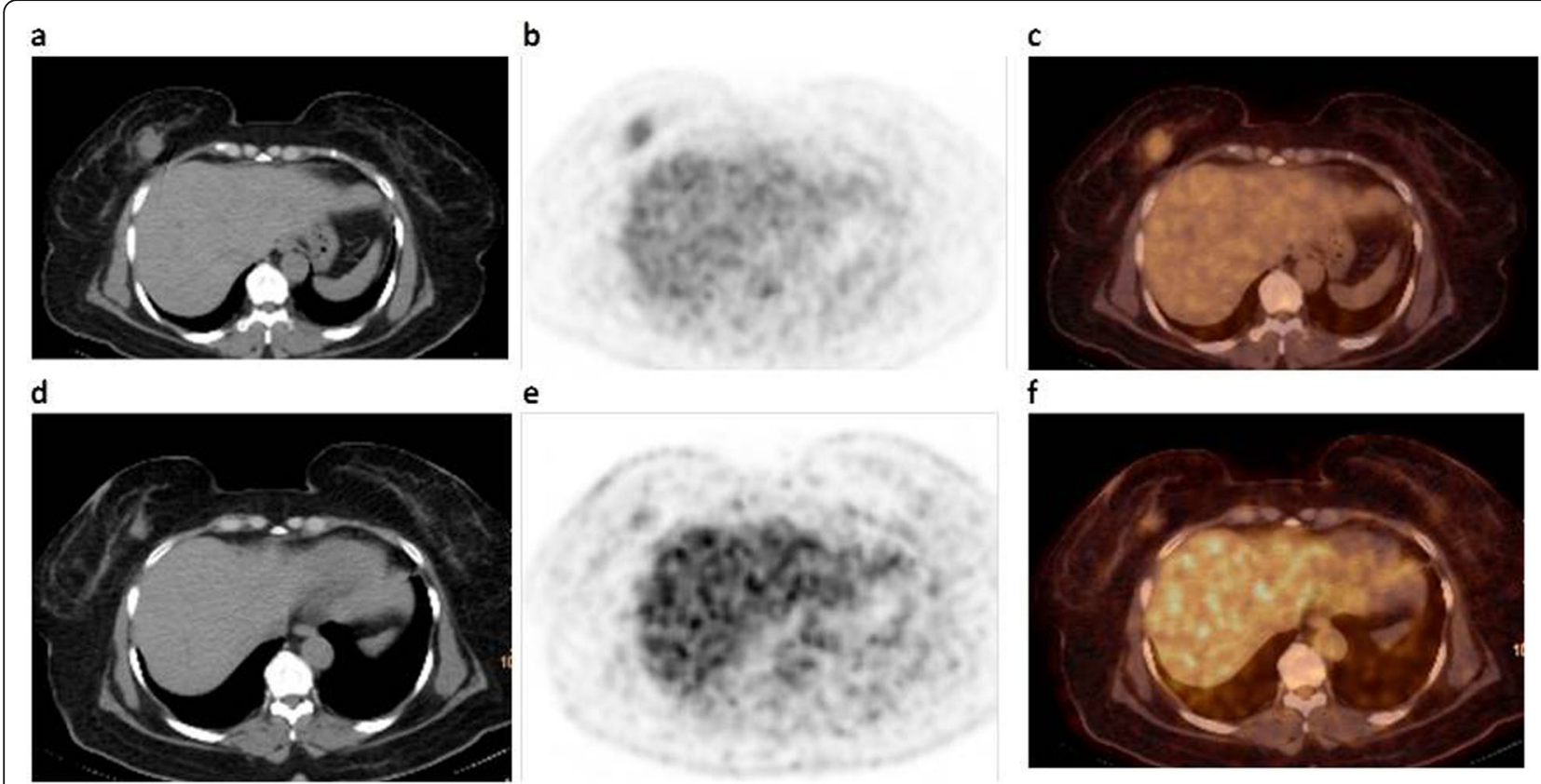

Fig. 468 years old female patient presented with right breast lump biopsy revealed invasive duct carcinoma grade II (luminal A subtype). Axial CECT image (a) revealed a rather defined right breast soft tissue mass lesion measuring about $29 \times 36 \mathrm{~mm}$ at lower inner quadrant that was eliciting increased tracer uptake reaching 5 SUL peak in axial PET (b) and fused PET/CT (c) images. On follow-up after completion of chemotherapy, morphologic and metabolic regression of the mass was noted in the form of reduction in size (reaching $9 \times 16 \mathrm{~mm}$ ) in axial CECT image (d) denoting partial response and reduction in SUL peak (reaching 2.1) in axial PET (e) and fused PET/CT (f) images denoting partial metabolic response

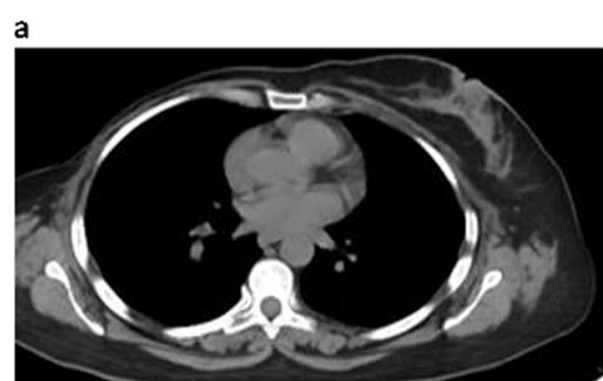

C

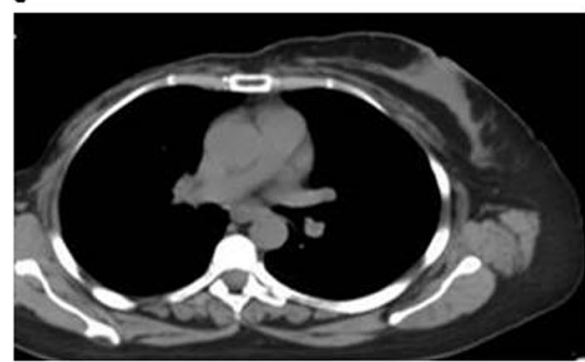

b

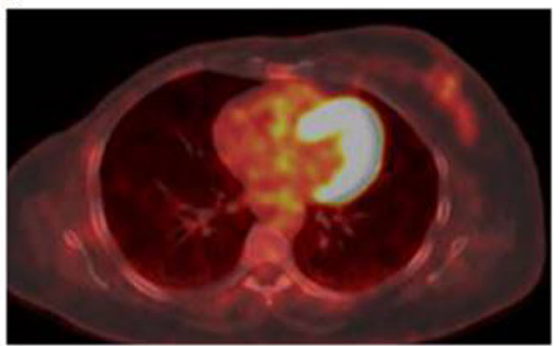

d

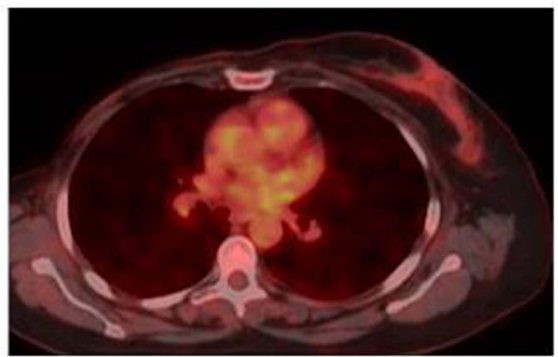

Fig. 556 years old female patient with history of right breast cancer submitted for MRM followed by chemotherapy presented with left breast cancer (invasive ductal carcinoma, luminal B subtype). Axial CECT and fused PET/CT images $(\mathbf{a}, \mathbf{b})$ revealed metabolically active left breast soft tissue mass lesion achieving 3 SUL $_{\text {peak. }}$ On follow-up after completion of chemotherapy, stationary appearance of the left breast mass regarding size and FDG uptake is noted in both axial CECT and fused PET/CT images $(\mathbf{c}, \mathbf{d})$ denoting stationary disease and stationary metabolic disease 


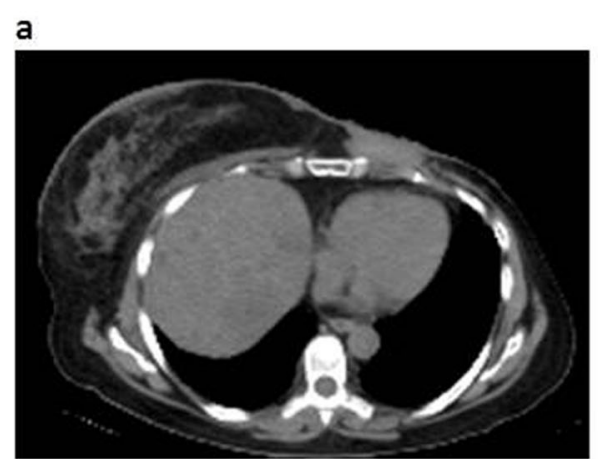

b

c

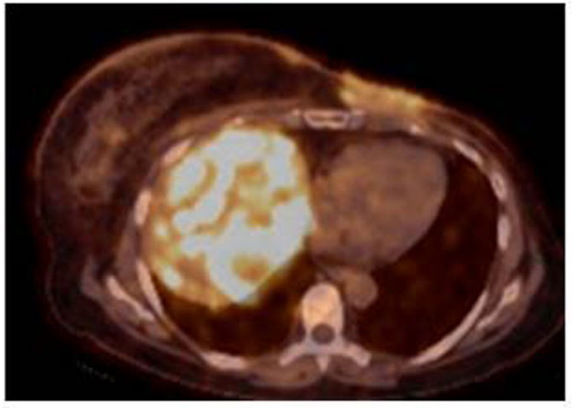

d
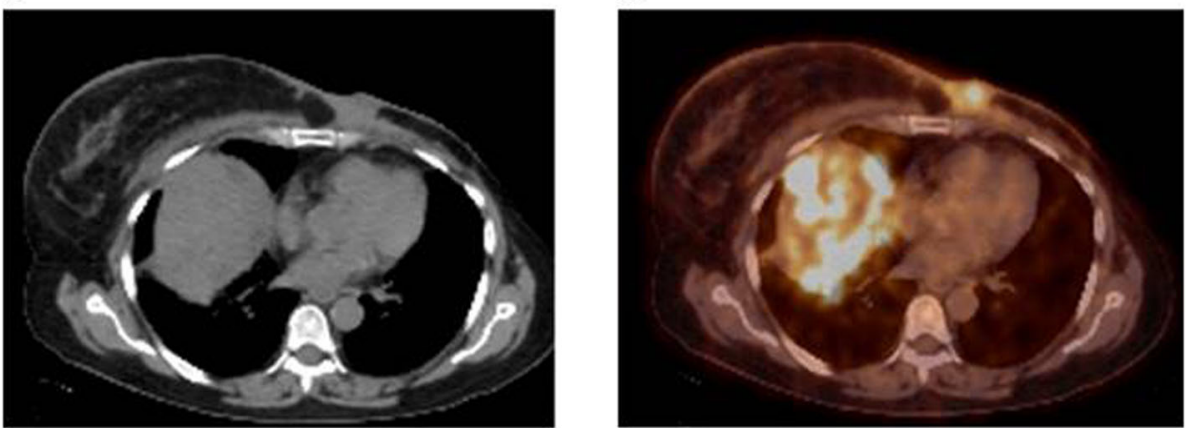

Fig. 656 years old female patient with history of left breast cancer, submitted for MRM followed by chemotherapy and hormonal treatment, presented with focal skin thickening at the operative bed, and histopathologicaly proven to be recurrent neoplasia (IDC basal subtype-tripple negative). Axial CECT and fused PET/CT images $(\mathbf{a}, \mathbf{b})$ revealed metabolically active soft tissue mass lesion measuring about $15 \times 46 \mathrm{~mm}$ and achieving 3.4 SUL peak. On follow-up after completion of chemotherapy, the lesion shows regression in size (measuring $19 \times 29 \mathrm{~mm}$ ) in axial CECT (c) denotin partial response, yet with progression in FDG uptake (achieving 6.4 SUL $\mathrm{L}_{\text {peak }}$ ) in fused PET/CT image (d) denoting progressive metabolic disease

Table 3 Tumor response according to RECIST 1.1, PERCIST 1.0, and histopathology

\begin{tabular}{ll}
\hline Response & No. of patients \\
\hline RECIST 1.1 & \\
Responders & $\mathbf{2 0}(\mathbf{6 6 . 7 \% )}$ \\
Non-responders & $\mathbf{1 0}(\mathbf{3 3 . 3} \%)$ \\
PERCIST $\mathbf{1 . 0}$ & \\
Responders & $\mathbf{2 3}(\mathbf{7 6 . 7 \% )}$ \\
CMR & $5(16.7 \%)$ \\
PMR & $18(60 \%)$ \\
Non-responders & $\mathbf{7 ( 2 3 . 3 \% )}$ \\
SMD & $4(13.3)$ \\
PMD & $3(10 \%)$ \\
Pathologic response & \\
Responders & $\mathbf{2 2}(\mathbf{7 3 . 3} \%)$ \\
Grade 3 & $14(46.7 \%)$ \\
Grade 4 & $4(13.3 \%)$ \\
Grade 5 & $4(13.3 \%)$ \\
Non-responders & $\mathbf{8 ( 2 6 . 7 \% )}$ \\
Grade 1 & $1(3.3 \%)$ \\
Grade 2 & $7(23.3 \%)$ \\
\hline
\end{tabular}

had sensitivity and specificity of $75 \%$ and may be useful in predicting the prognosis because none of the patients with a complete response in PET/CT exhibited recurrence. The false positivity was established in 3 out of 15 patients with pCR. Furthermore, out of the 20 patients with a complete response in PET/CT, 12 exhibited true positivity, and 8 exhibited false positivity. There was no significant difference between the mean pretreatment $\mathrm{SUV}_{\max }$ values of the patients with or without pCR. There was a significant relationship between the posttreatment $\mathrm{SUV}_{\max }$ value and pCR [3].

Although maximum or average SUV has been used in many studies for quantification of tumor FDG uptake, yet, they have specific limitations, and therefore PERCIST criteria used peak SUV (activity concentration in an approximately $1.0 \mathrm{~cm}$ volume) corrected for lean body mass (SUL peak ), instead of maximum SUV corrected for body weight, to avoid these limitations [27, 28]. PERCIST criteria quantifies therapeutic response as percent change in $S L_{\text {peak }}$ of the most intense lesion between the baseline and post-treatment ${ }^{18} \mathrm{~F}$-FDG PET scans and requires a change greater than $30 \%$ to distinguish PMR from SMD and PMD [29]. 


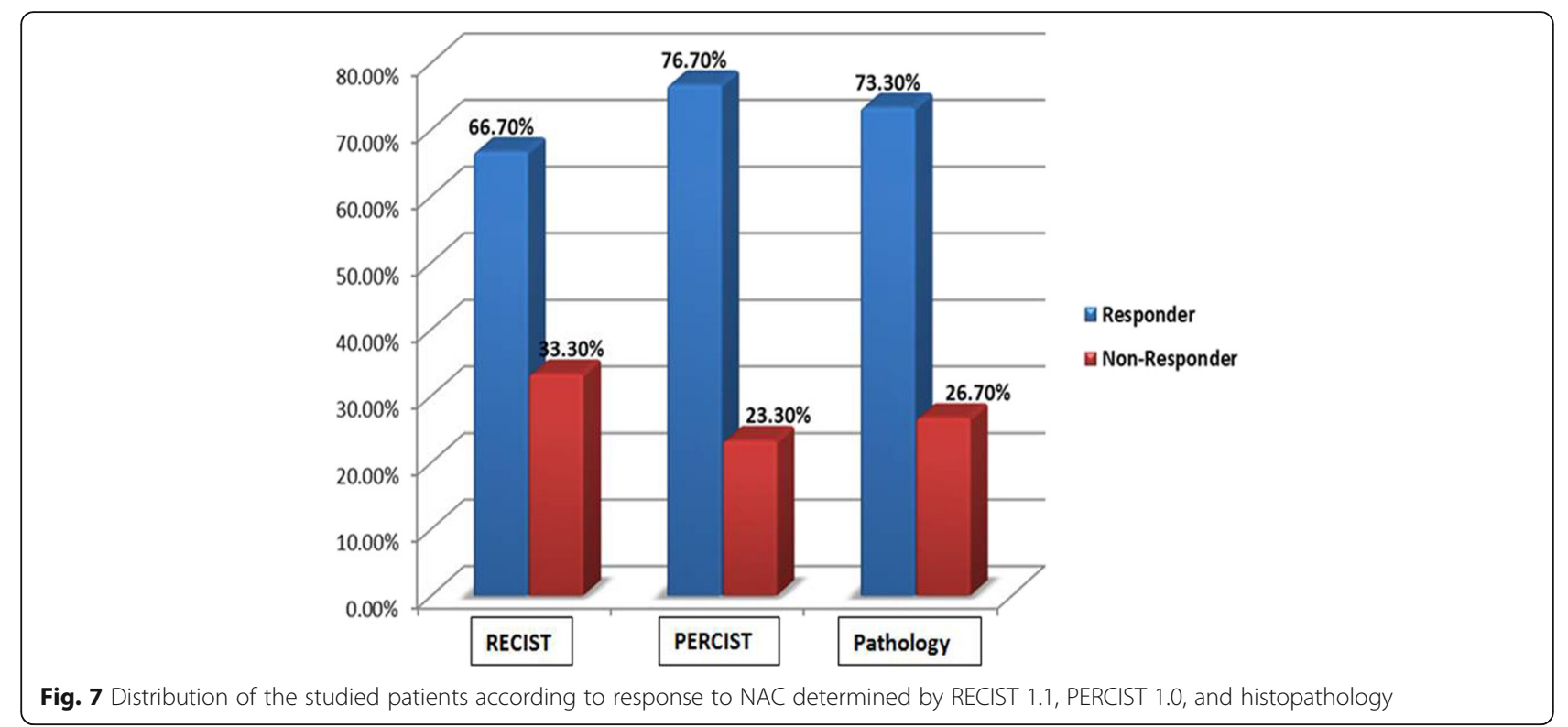

In the current study, we also correlated our results with the histopathological findings to evaluate accuracy of PET/CT in NAC response monitoring. After neoadjuvant chemotherapy, PET/CT showed 23 responders and 7 non-responders according to the PERCIST 1.0 criteria. Five patients showed complete metabolic response, and eighteen patients showed partial metabolic response (of the 23 responders), while 3 cases showed stable disease and 4 cases showed progressive disease (of the 7 nonresponders). Among the 23 responders, 21 were true positive, and 2 were false positive. Among the 7 non-

Table 4 Relationship between demographic/histopathologic features and pre-NAC tumor size

\begin{tabular}{|c|c|c|c|c|c|}
\hline \multirow[t]{2}{*}{ Characteristics } & \multicolumn{4}{|c|}{ Pre-NAC tumor size } & \multirow[t]{2}{*}{$\boldsymbol{P}$ value } \\
\hline & Mean & SD & Range & Median & \\
\hline \multicolumn{6}{|l|}{ Age (years) } \\
\hline$\leq$ median 54 & 3.38 & 1.43 & $1.6-6.6$ & 3.6 & \multirow[t]{2}{*}{${ }^{\mathrm{a}} 0.917$} \\
\hline$>$ median 54 & 3.57 & 1.31 & $1.7-5.7$ & 3.5 & \\
\hline \multicolumn{6}{|l|}{ Menopausal status } \\
\hline Pre-menopause & 3.92 & 1.48 & $1.6-6.6$ & 4 & \multirow[t]{2}{*}{${ }^{\mathrm{a}} 0.341$} \\
\hline Post-menopause & 3.42 & 1.26 & $1.6-5.7$ & 3.3 & \\
\hline \multicolumn{6}{|l|}{ Tumor grade } \\
\hline$\|$ & 3.43 & 1.26 & $1.6-5.7$ & 3.6 & \multirow[t]{2}{*}{0.305} \\
\hline III & 3.94 & 1.49 & $2-6.6$ & 3.9 & \\
\hline \multicolumn{6}{|c|}{ Tumor molecular type } \\
\hline Luminal A & 3.8 & 1.3 & $1.6-6.6$ & 3.8 & \multirow[t]{4}{*}{${ }^{b} 0.582$} \\
\hline Luminal B & 3.3 & 1.5 & $1.7-5.7$ & 2.9 & \\
\hline HER-2 + & 3.2 & 1.9 & $1.6-5.7$ & 2.8 & \\
\hline Basal type & 4.0 & 1.2 & $2.5-5$ & 4.8 & \\
\hline
\end{tabular}

${ }^{a}$ Mann-Whitney $U$ test

${ }^{\mathrm{b}}$ Kruskal-Wallis test (KW) responders, 6 were true negative, and 1 was false negative. Therefore, the sensitivity, specificity, and accuracy of PET/CT for NAC response evaluation were 95.5\%, $75 \%$, and $90 \%$, respectively, compared to $81.8 \%, 75 \%$, and $80 \%$, respectively, achieved by CT alone.

Tateishi et al. also showed that RECIST 1.1 had a sensitivity of $45.5 \%$, specificity of $85.5 \%$, and accuracy of $82.4 \%$, while those values for PERCIST 1.0 were $70.4 \%$, $95.7 \%$, and $90.8 \%$, respectively [4]. However, in another study by Kitajima et al. compared the response classifications RECIST 1.1 and PERCIST 1.0 used to determine

Table 5 Relationship between demographic/histopathologic features and post-NAC tumor size

\begin{tabular}{|c|c|c|c|c|c|}
\hline \multirow[t]{2}{*}{ Characteristics } & \multicolumn{4}{|c|}{ Post-NAC tumor size } & \multirow[t]{2}{*}{$\boldsymbol{P}$ value } \\
\hline & Mean & SD & Range & Median & \\
\hline \multicolumn{6}{|l|}{ Age (years) } \\
\hline$\leq$ median 54 & 2.2 & 1.9 & $0.0-7.6$ & 1.5 & \multirow[t]{2}{*}{${ }^{\mathrm{a}} 0.491$} \\
\hline$>$ median 54 & 2.3 & 1.1 & $1.1-5$ & 1.9 & \\
\hline \multicolumn{6}{|l|}{ Menopausal status } \\
\hline Pre-menopause & 1.9 & 1.5 & $0.0-5.6$ & 1.5 & \multirow[t]{2}{*}{${ }^{\mathrm{a}} 0.385$} \\
\hline Post-menopause & 2.5 & 1.8 & $0.0-7.6$ & 1.9 & \\
\hline \multicolumn{6}{|l|}{ Tumor grade } \\
\hline$\|$ & 2.1 & 1.8 & $0.0-7.6$ & 1.5 & \multirow[t]{2}{*}{${ }^{\mathrm{a}} 0.305$} \\
\hline III & 2.5 & 1.4 & $0.0-5.6$ & 2.5 & \\
\hline \multicolumn{6}{|c|}{ Tumor molecular type } \\
\hline $\begin{array}{l}\text { Luminal A } \\
\text { Luminal B } \\
\text { HER-2 }+ \\
\text { Basal type }\end{array}$ & $\begin{array}{l}2.7 \\
1.7 \\
1.6 \\
2.2\end{array}$ & $\begin{array}{l}1.9 \\
1.7 \\
1.2 \\
0.4\end{array}$ & $\begin{array}{l}0.0-7.6 \\
0.0-5 \\
0.0-3 \\
1.8-2.5\end{array}$ & $\begin{array}{l}2.5 \\
1.3 \\
1.7 \\
2.5\end{array}$ & ${ }^{b} 0.113$ \\
\hline
\end{tabular}

a Mann-Whitney $U$ test

${ }^{\mathrm{b}}$ Kruskal-Wallis test (KW) 
Table 6 Relationship between demographic/histopathologic features and pre-NAC tumor SUL

\begin{tabular}{|c|c|c|c|c|c|}
\hline \multirow[t]{2}{*}{ Characteristics } & \multicolumn{4}{|c|}{ Pre-NAC tumor $S U L_{\text {peak }}$} & \multirow[t]{2}{*}{$\boldsymbol{P}$ value } \\
\hline & $\overline{\text { Mean }}$ & SD & Range & Median & \\
\hline \multicolumn{6}{|l|}{ Age (years) } \\
\hline$\leq$ median 54 & 6.6 & 4.3 & $2.5-15$ & 5.2 & \multirow[t]{2}{*}{${ }^{\mathrm{a}} 0.215$} \\
\hline$>$ median 54 & 7.5 & 3.1 & $2.8-13.7$ & 7.6 & \\
\hline \multicolumn{6}{|l|}{ Menopausal status } \\
\hline Pre-menopause & 6.6 & 4.3 & $2.5-15$ & 5.1 & \multirow[t]{2}{*}{${ }^{\mathrm{a}} 0.341$} \\
\hline Post-menopause & 7.3 & 3.5 & $2.5-14.1$ & 6.7 & \\
\hline \multicolumn{6}{|l|}{ Tumor grade } \\
\hline$\|$ & 6.5 & 3.5 & $2.5-14.1$ & 5.4 & \multirow[t]{2}{*}{${ }^{\mathrm{a}} 0.573$} \\
\hline III & 7.6 & 4.3 & $2.5-15$ & 6.6 & \\
\hline \multicolumn{6}{|c|}{ Tumor molecular type } \\
\hline Luminal A & 6.1 & 3.4 & $2.5-14.1$ & 5.1 & \multirow[t]{4}{*}{${ }^{b} 0.549$} \\
\hline Luminal B & 7.3 & 2.6 & $4.7-12$ & 6.9 & \\
\hline HER-2 + & 6.9 & 5.6 & $2.8-15$ & 5.1 & \\
\hline Basal type & 9.2 & 4.7 & $4.5-14.4$ & 9.1 & \\
\hline
\end{tabular}

a Mann-Whitney $U$ test

${ }^{b}$ Kruskal-Wallis test (KW)

pathological response to NAC in breast cancer patients, PERCIST 1.0 showed higher levels of sensitivity and NPV, but lower levels of specificity, PPV, and accuracy when compared to RECIST 1.1 [11].

In several studies, the ${ }^{18} \mathrm{~F}$-FDG uptake values found to be related to tumor biology in various malignancies. Studies comparing the ${ }^{18}$ F-FDG uptake with histopathological parameters in breast cancer showed that the ${ }^{18} \mathrm{~F}$ -

Table 7 Relationship between demographic / histopathologic features and post-NAC tumor SUL

\begin{tabular}{|c|c|c|c|c|c|}
\hline \multirow[t]{2}{*}{ Characteristics } & \multicolumn{4}{|c|}{ Post-NAC tumor SUL peak } & \multirow[t]{2}{*}{$\boldsymbol{P}$ value } \\
\hline & Mean & SD & Range & Median & \\
\hline \multicolumn{6}{|l|}{ Age (years) } \\
\hline$\leq$ median 54 & 3.7 & 5.6 & $0.0-24.7$ & 2.3 & \multirow[t]{2}{*}{${ }^{\mathrm{a}} 0.491$} \\
\hline$>$ median 54 & 3.2 & 1.8 & $1.3-8.1$ & 2.5 & \\
\hline \multicolumn{6}{|l|}{ Menopausal status } \\
\hline Pre-menopause & 2.5 & 2.0 & $0.0-5.8$ & 2.1 & \multirow[t]{2}{*}{${ }^{\mathrm{a}} 0.385$} \\
\hline Post-menopause & 4.3 & 5.6 & $0.0-24.7$ & 2.5 & \\
\hline \multicolumn{6}{|l|}{ Tumor grade } \\
\hline$\|$ & 3.9 & 5.6 & $0.0-24.7$ & 2.4 & \multirow[t]{2}{*}{${ }^{\mathrm{a}} 0.305$} \\
\hline III & 2.9 & 1.5 & $0.0-5.8$ & 2.7 & \\
\hline \multicolumn{6}{|c|}{ Tumor molecular type } \\
\hline Luminal A & 4.3 & 5.9 & $0.0-24.7$ & 2.5 & \multirow[t]{4}{*}{${ }^{b} 0.113$} \\
\hline Luminal B & 3.1 & 2.7 & $0.0-8.1$ & 2.5 & \\
\hline HER-2+ & 1.9 & 1.3 & $0.0-2.8$ & 2.4 & \\
\hline Basal type & 2.7 & 0.9 & $1.9-3.9$ & 2.3 & \\
\hline
\end{tabular}

a Mann-Whitney $U$ test

${ }^{\mathrm{b}}$ Kruskal-Wallis test (KW)
FDG uptake values are lower in invasive lobular carcinomas than that in invasive ductal carcinomas. This was attributed to lower intensity of tumor cells in lobular carcinomas, diffuse infiltrative tumor growth patterns, and lower proliferation rates [30]. A comparison could not be made in this study owing to the low number of included patients with invasive lobular carcinoma (one patient).

No significant relationship was observed between the menopausal status of the patient and $\mathrm{SUL}_{\text {peak }}$ in our study. Although a study by Groheux et al. revealed that the ${ }^{18}$ F-FDG uptake value was 1.3 times higher in premenopausal patients, another study by Kim et al revealed that menopausal status and tumor FDG uptake values were independent [30, 31].

The tumor grade is a significant predictive factor in breast carcinomas. A strong positive correlation has been detected between the ${ }^{18}$ F-FDG uptake levels and histological grade in a study done by Ekmekcioglu et al. [32]. Although the mean $\mathrm{SUL}_{\text {peak }}$ values of patients with a grade III disease was higher in our study ,yet, no relationship between the tumor grade and $\mathrm{SUL}_{\text {peak }}$ values was observed, possibly because of the limited number of patients.

The main limitation of our study was the relatively small sample size due to the high cost of the technique. Therefore, a future prospective trial recruiting a larger number of patients will more clearly define the role of PET/CT-based evaluation of treatment response with more accurate results. Furthermore, only primary breast lesions were analyzed to assess tumor response. In addition, follow-up PET/CT was done in this study after finishing the chemotherapy, while many other studies performed serial PET/CT in the beginning of and during chemotherapy, determining the benefits of administering a new chemotherapy regimen versus prolonged administration of the same chemotherapy regimen in nonresponders.

\section{Conclusion}

${ }^{18} \mathrm{~F}-\mathrm{FDG} \mathrm{PET} / \mathrm{CT}$ is a reliable single whole body imaging tool which can be used in monitoring of NAC response (using PERCIST 1.0) in patients with locally advanced breast cancer showing higher sensitivity and accuracy compared to CT alone (using RECIST 1.1).

\footnotetext{
Abbreviations

${ }^{18}$ F-FDG: ${ }^{18}$ F-Fluorodeoxyglucose; PET/CT: Positron emission tomography/ computed tomography; RECIST: Response Evaluation Criteria In Solid Tumor; PERCIST: PET Response Criteria In Solid Tumor; CR: Complete response; CMR: Complete metabolic response; PR: Partial response; PMR: Partial metabolic response; SD: Stationary disease; SMD: Stationary metabolic disease; PD: Progressive disease; PMD: Progressive metabolic disease; pCR: Pathologic complete response; mg/dL: Milligram per deciliter; mCi: Millicurie; Kg: Kilogram; mL: Milliliter; mA: Milliampere; kV: Kilovolt; $\mathrm{s}$ : Second; mm: Millimetre
} 


\section{Acknowledgements}

Not applicable

\section{Authors' contributions}

EA carried out the PET/CT studies and collected the data. SA, LA, and MI participated in the design of the study. EA performed the statistical analysis, and SA drafted the manuscript. All authors read and approved the final manuscript.

\section{Funding}

This work has not received any funding.

\section{Availability of data and materials}

All data generated or analyzed during this study are included in this article.

\section{Ethics approval and consent to participate}

The study protocol was approved by the Ethical Committee of Ain Shams University (no reference number was given), and written informed consent was obtained from all patients' parents to participate in the study.

\section{Consent for publication}

Written informed consent was obtained from all patients' parents for publication of the study.

\section{Competing interests}

The authors declare that they have no competing interests.

\section{Author details}

${ }^{1}$ International Medical Center, Cairo, Egypt. ${ }^{2}$ Radiodiagnosis Department, Ain Shams University, Cairo, Egypt.

Received: 1 April 2020 Accepted: 26 June 2020

Published online: 07 July 2020

\section{References}

1. Taghipour M, Wray R, Sheikhbahaei S, Wright JL, Subramaniam RM (2016) FDG avidity and tumor burden: survival outcomes for patients with recurrent breast cancer. AJR Am J Roentgenol 206(4):846-855

2. El Bakry M, Sultan A, El-Tokhy N (2015) Role of diffusion weighted imaging and dynamic contrast enhanced magnetic resonance imaging in breast tumors. EJRNM 46:791-804

3. Yildirim N, Simsek M, Aldemin MN, Bilici M, Tekin SB (2019) The relationship between 18-FDG-PET/CT and clinicopathologic features, pathologic response in patients with locally advanced breast cancer. Eurasian J Med 51(2):154-159

4. Tateishi U, Miyake M, Nagaoka T et al (2012) Neoadjuvant chemotherapy in breast cancer: prediction of pathologic response with PET/CT and dynamic contrast enhanced MR imaging-prospective assessment. Radiology 263:5363

5. Ali SA, Abd Elkhalek YI (2016) Added value of combined 18F-FDG PET/ CT for detection of osseous metastases in cancer patients. EJRNM 47(2):453458

6. Groheux D, Espie M, Giacchette and Hindie E (2013) Performance of FDG PET/CT in management of breast cancer. Radiology 266: 388-405.

7. Ali SA, Abd Elkhalek YI (2016) Value of integrated PET/CT in detection of hepatic metastatic deposits. EJRNM 47(2):459-465

8. Fletcher JW, Djulbegovic B, Soares HP et al (2008) Recommendations on the use of 18F-FDG PET in oncology. J Nucl Med 49:480-508

9. Ali SA, Hamed MA (2017) The diagnostic efficacy of whole body 18 FFDG PET CT in detection of unexpected second primary malignancy in cancer patients. EJRNM 48(3):671-676

10. Shang J, Ling $X$, Zhang L et al (2016) Comparison of RECIST, EORTC criteria and PERCIST for evaluation of early response to chemotherapy in patients with non-small-cell lung cancer. Eur J Nucl Med Mol Imaging 43:1945-1953

11. Kitajima K, Miyoshi Y, Yamano T et al (2018) Assessment of tumor response to neoadjuvant chemotherapy in patients with breast cancer using MRI and FDG-PET/CT-RECIST 1.1 vs. PERCIST 1.0. Nagoya J. Med. Sci. 80:183-197

12. Pinker K, Riedl C, Weber WA (2017) Evaluating tumor response with FDG PET: updates on PERCIST, comparison with EORTC criteria and clues to future developments. Eur J Nucl Med Mol Imaging 44:55-66
13. Fragomeni SM, Sciallis A, Jeruss JS (2018) Molecular subtypes and localregional control of breast cancer. surgical oncology clinics of. North America 27(1):95-120

14. Mukherjee P, Sharma S, Sheikh ZA, Vijaykumar DK (2014) Correlation of clinico-pathologic and radiologic parameters of response to neoadjuvant chemotherapy in breast cancer. Indian Journal of Cancer 51(1):25-29

15. Koo HR, Park JS, Kang KW, Han W, Park IA, Moon WK (2015) Correlation between 18F-FDG uptake on PET/ CT and prognostic factors in triplenegative breast cancer. Eur Radiol 25:3314-3321

16. Lee HW, Lee HM, Choi S-E, Yoo H, Ahn SG, Lee M-K et al (2016) The prognostic impact of early change in standardized uptake value of $18 \mathrm{~F}$ fluorodeoxyglucose positron emission tomography after neoadjuvant chemotherapy in locally advanced breast cancer patients. J Nucl Med. 57: 1183-1188

17. Rousseau C, Devillers A, Sagan C, Ferrer L, Bridji B, Campion L et al (2006) Monitoring of early response to neoadjuvant chemotherapy in stage $I I$ and III breast cancer by [18F] fluorodeoxyglucose positron emission tomography. J Clin Oncol 24:5366-5372

18. Mansour MG, Ali SA (2016) Transarterial chemoembolization using drug eluting microspheres in refractory colorectal liver metastases with 18F-FDG PET/CT follow-up to assess therapeutic response. EJRNM 47(4):1467-1472

19. Ali SA, Abdelkawi MM, Hussien NM (2019) Delayed post-diuretic 18FFDG PET/CT: can it help in determination of the best clinical decision for muscle invasive UB cancer patients? EJRNM 50:111

20. Ege Aktas G, Taştekin E, Sarikaya A (2018) Assessment of biological and clinical aggressiveness of invasive ductal breast cancer using baseline $18 \mathrm{~F}$ FDG PET/CT-derived volumetric parameters. Nucl Med Commun 39:83-93

21. Riedl CC, Pinker K, Ulaner GA et al (2017) Comparison of FDG-PET/CT and contrast-enhanced $C T$ for monitoring therapy response in patients with metastatic breast cancer. Eur J Nucl Med Mol Imaging 44:1428-1437

22. Ali SA, Amin DH, Abdelkhalek YI (2020) Efficiency of whole-body 18F-FDG PET $C T$ in detecting the cause of rising serum AFP level in post-therapeutic followup for HCC patients. Jpn J Radiol. https://doi.org/10.1007/s1 1604-020-00930-8

23. Dose-Schwarz J, Tiling R, Avril-Sassen S, Mahner S, Lebeau A, Weber and Avril N (2009) Assessment of residual tumour by FDG-PET: conventional imaging and clinical examination following primary chemotherapy of large and locally advanced breast cancer. British Journal of Cancer 102(1): 35-41.

24. Jones EF, Ray KM, Li W, Seo Y, Franc BL, Chien AJ, Hylton NM (2017) Dedicated breast positron emission tomography for the evaluation of early response to neoadjuvant chemotherapy in breast cancer. Clinical Breast Cancer 17(3):e155-e159

25. Coudert B, Pierga JY, Mouret-Reynier MA et al (2014) Use of 18F-FDG PET to predict response to neoadjuvant trastuzumab and docetaxel in patients with HER2-positive breast cancer, and addition of bevacizumab to neoadjuvant trastuzumab and docetaxel in 18F-FDG PET-predicted nonresponders (AVATAXHER): an open-label, randomised phase 2 trial. Lancet Oncol 15:1493-1502

26. Pahk K, Rhee S, Cho J, Seo M, Lee S, Park T et al (2014) The role of interim18F-FDG PET/CT in predicting early response to neoadjuvant chemotherapy in breast cancer. Anticancer Res 34(8):4447-4455

27. Wahl RL, Jacene $H$, Kasamon Y, Lodge MA (2009) From RECIST to PERCIST: evolving considerations for PET response criteria in solid tumors. J Nucl Med 50(Suppl 1):122S-150S

28. O JH, Lodge MA and Wahl RL (2016) Practical PERCIST: a simplified guide to PET Response Criteria in Solid Tumors 1.0. Radiology 280(2): 576-584.

29. Harrison RL, Elston BF, Doot RK, Lewellen TK, Mankoff DA, Kinahan PE (2014) A virtual clinical trial of FDG-PET imaging of breast cancer: effect of variability on response assessment. Transl Oncol 7(1):138-146

30. Groheux D, Giacchetti S, Moretti JL et al (2011) Correlation of high 18F-FDG uptake to clinical, pathological and biological prognostic factors in breast cancer. Eur J Nucl Med Mol Imaging 38:426-435

31. Kim BS, Sung SH (2012) Usefulness of 18F-FDG uptake with clinicopathologic and immunohistochemical prognostic factors in breast cancer. Ann Nucl Med 26:175-183

32. Ekmekcioglu O, Aliyev A, Yilmaz $S$ et al (2013) Correlation of 18Ffluorodeoxyglucose uptake with histopathological prognostic factors in breast carcinoma. Nucl Med Commun 34:1055-1067

\section{Publisher's Note}

Springer Nature remains neutral with regard to jurisdictional claims in published maps and institutional affiliations. 